\title{
Can Modern E-Learning Development Follow a Process That Ensures Quality?
}

\author{
Gregory C. Sales \\ Seward Incorporated, United States
}

For more than 30 years l've been involved in the design, development, and evaluation of technology-based learning (that's what we called the predecessor to e-learning). Early in my career, I was introduced to a troubling adage used to describe an approach to the creation of education and training products. The adage is:

Good, fast, cheap - pick two.

This saying suggests that a product cannot be high quality and produced quickly while remaining economical.

As a professional, I was originally offended by the saying, thinking it crude and simplistic. However, it has stayed in my consciousness over the years. It continues to surprise and sadden me how frequently it can be used to describe the approach taken to the design of e-learning products.

I have worked with well over a hundred clients representing public education, higher education, healthcare, manufacturing, sales, government agencies, and international development donors. I have been involved in the production of thousands of hours of courseware. In my experience, I estimate the adage has been unknowingly applied more than $95 \%$ of the time. It's the rare project that has a generous budget, is free of time pressures, and has the goal of producing the best possible instruction.

Recent innovations in the field, such as the advent of learning content management systems, creation of learning object repositories, and development of production environments that eliminate the need for programming skills have gone a long way toward making the production of e-learning easier. Consequently, many individuals and organizations have perceived that with a little bit of training, anyone can create e-learning ... and they do.

Authors use these newly available resources to produce fast and cheap e-learning products. When these products are facilitated courses, facilitators can insert themselves to fill the content voids, correct inaccurate information, or address functionality issues. When the products are stand-alone courses, however, learners suffer. They become frustrated, are forced to seek out means of supplementing the instruction, and may ultimately discontinue with the course - leaving in frustration and dismay. 
Traditionally, the stand-alone e-learning development process has attempted to avoid these problems by being a team effort. In the traditional development process, one or more subject matter experts (SMEs) provide content, instructional designers work with the SMEs to determine/design the most effective methods for delivery of the content, media production teams (e.g. artists, animators, videographers, voice talent) participate in creation of a creative treatment and produce the assets as required by the design, programmers/developers assemble the assets according to the design document specification, and a quality assurance procedure is implemented to identify and address deficiencies in the content presentation, software functionality, and overall product appeal. Criticisms of this process are that it can be slow or expensive, and that it produces learning that is boring or unimaginative. Recognized strengths of the approach are that it creates products that are complete, accurate, and instructionally effective.

Is it possible to blend the best of the modern and traditional approaches to create more powerful e-learning products? I suggest that such a process could be created. It would be one that requires more discipline then is often undertaken in modern course development. It may also take a little longer to implement this process. However, I have every reason to believe that such a process would result in much better products - happier learners, more learning, and better attitudes about e-learning courses.

I propose that to create quality e-learning in the modern environment, five critical concepts must be recognized and accepted. These concepts are: 1) instructional design principles and procedure do exist and can positively affect the quality of e-learning products, 2) not all subject matter experts are instructional designers so they should be partnered with someone who has the expertise to design e-learning, 3) saving money on development through the use of free content elements may ultimately cost even more money if learners become disengaged or the desired learning outcomes are not achieved, 4) a systematic approach to design and development is needed to ensure that accurate and thorough learning environments are created, and, 5) a balance of quality, efficiency and economy is achievable through the implementation of a cost benefit analysis.

The application of these concepts can result in a process that utilizes the convenience of available resources without forsaking the established cornerstones of quality instructional development. The ultimate goal of every development effort should be the creation of the best possible instruction for the specific needs, produced in the most cost effective manner, at the lowest practical cost.

Correspondence: Gregory C. Sales, President and CEO, Seward Incorporated, 2200 East Franklin Avenue, Minneapolis, MN 55404, United States. 